\title{
"Diabesity" among Latinos: A Culturally Relevant Mathematics Activity by a Mathematics Teacher Candidate
}

\author{
Olga Ramirez, Ph.D. \\ Amanda Carranza-Alvarez. B. S. \\ University of Texas - Rio Grande Valley \\ McAllen, Texas, USA \\ Cherie McCollough, Ph.D. \\ Texas A\&M University - Corpus Christi \\ Corpus Christi, Texas, USA
}

\begin{abstract}
This paper summarizes a culturally relevant mathematics project conducted by a mentored secondary-level Latino teacher candidate (TC) as a requirement for an undergraduate mathematics project course at a south Texas university. The culturally relevant math project involved four secondary Latino students and their parents. The topic was "diabesity"; that is, diabetes and obesity among Latinos southern region in the United States of America with an emphasis on body mass index, proper diet, and exercise. Remarks by the faculty mentor and a faculty consultant about the TC work and reflections regarding this project are also included and provide perspectives on how to address cultural connections with mathematics.
\end{abstract}

Keywords: culturally relevant mathematics; mathematics and health; mathematics education; culturally relevant teaching; family learning event.

\section{Review of the Literature}

Dr. Gloria Ladson-Billings' $(2014,2018)$ work on culturally relevant pedagogy has had an impact on how teacher candidates (TCs) are prepared. Her work regarding the African-American population and their culture has influenced numerous educators to prepare future teachers with educational experiences that equitably support all students, whites and non-whites. LadsonBillings has stipulated that teachers should systematically include relevant student experiences that recognize cultures of minority students in the classroom as authorized or official knowledge. This is a must in preparing all teachers to enhance educational practices that will match with the children's culture in ways that ensure strong academic behaviors. These practices aim to minimize the inferior education provided for minorities and students of low 
socioeconomic status caused, in large measure, by the basic ethnocentrism of the dominant strata of whites in American society (Valenzuela, 2016). The culturally relevant practices apply to Latinos because aside from being the largest and fastest growing minority in the USA, this population remains among the most educationally disadvantaged ethnic group (Potter \& Morris, 2016). Research indicates that Latino students perform lower on measures of academic achievement on national, regional, state and local reports (Valenzuela, 2016).

To improve these conditions, research and national policies have identified parental involvement and culturally relevant pedagogy as critical components of public education in the United States, particularly in the schooling of Hispanic students (Epstein, Jung \& Sheldon, 2018;Grant, 2018; National Research Council, 2013; Valenzuela, 2016). There is evidence that parental involvement and culturally relevant pedagogy lead to improvement in student achievement, increased student attendance, and reduced dropout rates (Epstein et al, 2018). Clark, et.al. (2015) and Zygmunt et al., (2018) propose new ways for teacher educators to incorporate culturally responsive programs whereby they contextualize understanding of culture, community, and identity of children and families. This is important in building community-based experiences that include students and parents rather than having ambiguous stand-alone or disconnected multicultural education programs. Consequently, parental involvement and culturally relevant pedagogy in the public schools is a venue that helps improve the quality of children's cultural and educational experiences (Zygmunt et al., 2018).

Despite this research, much of the literature states that educators who encounter race or cultural issues are often not getting the preparation they need. Olivos and Mendoza (2010) and the Epstein et al. (2018) stipulate that forging effective home-school partnerships requires teacher preparation programs to actively address issues concerning language differences, cultural understandings of families, and parents' sense of self-efficacy to help their children with schoolwork. Thus, educator preparation programs should include more than superficial readings about cultural differences. Instead, teacher preparation programs should include modeling student-centered, culturally relevant pedagogy curriculum and less traditional didactic instruction in mathematics content (Clark, et al., 2015; Settlage \& Southerland, 2018)

In efforts to include culturally relevant pedagogy, the author-educators (Ramirez, McCollough \& Dias, 2016, 2015; Ramirez \& McCollough, 2012; McCollough, Ramirez \& Carranza-Alvarez, 2018; McCollough \& Ramirez, 2012; McCollough, 2011;) have provided their TCs opportunities to work with different culturally relevant mathematics and science activities that promote recognition and pride for the Latino culture. These pedagogical opportunities include culturally relevant authentic practices by using Family Learning Events to incorporate culturally relevant teaching with students and their parents. Their central organizing concept and aim has been to use culturally relevant pedagogy and content with mathematics and science topics. The overall goal is to prepare TCs to engage in school family learning events involving parents with the culture of Latino children with math and science activities in ways that will produce future teachers who are trained to teach with culturally relevant instruction and pedagogy. 
The challenge to further develop a model for TCs to interact with school age children and their non-English speaking Latino parents using culturally relevant mathematics activities motivated the faculty to mentor a TC of Latino heritage, at her request, and who was enrolled in a mathematics project class in the final year of her studies. The "diabesity" CRM project provided the participants with information about the diseases relevant to their cultural background. It included how the Body Mass Index is calculated and what information it offers concerning weight categories (CDC:BMI, 2015), how poor dieting increases the likelihood of developing both of these diseases (Healthline, 2012), and how different exercises and the calories burned by performing them can help improve health and normalize weight (What's Cooking America, 2015; CDC: Physical Activity, 2015). With guidance by the faculty mentor, the TC developed, implemented the activities and several surveys that were completed by the participants to study the participants' reactions before and after the CRM project.

The following paper summarizes a culturally relevant mathematics (CRM) project on "diabesity" which the mentored TC conducted with four Latino students and their parents in an afterschool event. The event was supported by the school campus principal and the school's Parental Engagement Committee. The purpose of this case study includes describing how a TC was mentored to develop and implement a CRM project using an authentic opportunity to help the TC understand and experience how culture connected to mathematics can shape teaching mathematics. The experience guided the TC in prioritizing cultural relevancy when teaching mathematics, and to see results from four secondary students and the parents learning mathematics with a cultural connection. Furthermore, this case study illustrates the potential impact on future mathematics teachers from the perspective of a TC and her faculty mentor and consultant experiencing the CRM project with math objectives that include a Latino cultural perspective.

\section{How the CRM Project was Conceived, Developed and Implemented}

The CRM project started on or about the second week of the semester with regular meetings and e-mail correspondence between the TC and the faculty mentor. Prior to the initial meeting, the TC reviewed several publications about CRM co-authored by the faculty mentor and consultant. The readings motivated her to know more about CRM and about how to develop and implement a CRM project for her mathematics course. At the meetings, they discussed different possible culturally relevant mathematics activities, including the "diabesity" activity. By the second meeting, the TC and the faculty mentor opted to focus on "diabesity", defined by diabetes and obesity among the Latino population (CDC: National Statistics, 2015) since both had an interest in the prevalence of these diseases among Latinos in their south Texas community. The TC and faculty mentor were born and raised within miles of each other in South Texas. The TC agreed to design the lesson plan and develop a Power Point file to introduce the participants with the topic of "diabesity", followed by a project using a culturally relevant math activity with plans to present on a scheduled presentation day to her peers and math faculty. 
The TC began the project by exploring the prevalence and impact of diabetes and obesity ("diabesity") among Latinos by researching the literature. The faculty mentor helped her to develop meaningful CRM activities that would be completed by four Latino students and their parents about body mass index, proper diet, exercise, and their relationship to "diabesity" among the Latino population. The TC, with approval by the faculty mentor, chose to involve her "alma mater" secondary school principal to help solicit participants for her project. Prior to beginning the presentation, pre-surveys were constructed and administered with consent forms to accompany data collection. Then, a 15minute PowerPoint presentation was designed to introduce powerful statistics about these diseases among Latinos (Texas Health and Human Services, 2019) on the day of the CRM activities. The CRM activities lasted approximately 2hours in duration and the student/parent teams used calculators and computers to complete CRM activities. Post-surveys followed the implementation of the CRM project. The TC and her faculty mentor then analyzed the pre- and postsurvey data to determine any changes in perceptions regarding mathematics and culture by the participants. Later, a meeting between the TC and her mentor was held to focus on answering the research questions that follow:

1. What mathematical content did the Latino secondary students, Latino parents and TC learn from the CRM project activities?

2. What cultural reactions did the Latino secondary students, Latino parents and the TC report experiencing from the CRM project activities?

In addition, the TC responded to the research questions in her own words by writing a semi-structured reflection paper regarding what she learned from this CRM project. Following this assignment, the TC created another Power Point file of the CRM project that she used to present to her peers and to mathematics faculty as required for the undergraduate mathematics project course.

\section{Background Information on Diabetes and Obesity for the CRM Project}

The following information derived primarily by the TC from multiple sources and reviewed by her faculty mentor is an introduction about diabetes and obesity for the CRM project. This section also highlights appalling statistics about these diseases among Latinos in south Texas, justifying the TC's choice for her CRM project.

Glucose is a blood sugar and is an important source of energy for the cells that make up muscles and tissues (Mayo Clinic, 2015). The pancreas releases insulin to help the body store and use glucose. Diabetes, or diabetes mellitus, is a disease that occurs when the pancreas does not produce any insulin or does not produce enough insulin, or the body does not respond appropriately to insulin (International Diabetes Federation, 2015). The four most commonly diagnosed types of diabetes are type 1 diabetes, where the body produces little to no insulin; type 2 diabetes, where the body cannot properly respond to the insulin produced and is insulin resistant; gestational diabetes, where the hormones during pregnancy affect the way that the body responds to insulin; and prediabetes, where the blood glucose level is higher than normal but not high enough to be diagnosed as diabetes (CDC: National Statistics, 2017; CDC: Diabetes, 2015; Endocrineweb, 2015; CDC: Prediabetes, 2015). Below are some 
shocking statistics collected from the America's Health Ranking: United Health Foundation (2018) dealing with diabetes and obesity in the South Texas population, and area with $90 \%+$ Latinos).

- The prevalence of adult diabetes in several South Texas counties is more than $20 \%$ higher than in the state of Texas.

- In South Texas, approximately 70,000 adults have diabetes, approximately $11 \%$ of the population.

- The South Texas population, when compared Texas State or the United States population (as defined by hemoglobin A1C levels), has a significantly higher rate of uncontrolled diabetes.

Obesity is a term used for a body mass index (BMI) of 30 or higher and more informally, obesity means having too much body fat. Unfortunately, under these circumstances a person's health is in danger (WebMD, 2014; CDC: Obesity, 2015). The worldwide rate of obesity has tripled since 1975. From 20142016, it is reported that more than 1.9 billion adults world-wide (18 years or older) were overweight. Of these, approximately $39 \%$ were overweight, and $13 \%$ were obese (World Health Organization, 2015). What is worse is that the prevalence of obesity in south Texas, the home area for the TC, has been noted as having the highest obesity rate in the nation (U.S. News and World Report 2018A; U.S. News and World, 2018B). Research states that a "lack of access to affordable healthy foods" is a strong contributor to the Latino's levels of obesity (The State of Obesity, 2015).

According to the U.S. Department of Health and Human Services Office of Minority Health (2013) the following alarming statistics describe the Hispanic population and obesity.

- In 2015, Hispanic Americans were 1.2 times as likely to be obese than non-Hispanic whites.

- From 2011-2014 Hispanic children were 1.8 times more likely to be overweight as non- Hispanic white children.

- From 2015, Hispanic women were 30\% more likely to be overweight, as compared to non-Hispanic whites

- In 2015, Hispanic adults were 30\% less likely to engage in active physical activity as non-Hispanic whites.

- Among Mexican American women, 77\% are overweight or obese, as compared to only $64 \%$ of the non-Hispanic White women.

According to Farag and Gaballa (2011) the risk of death is increased 20$40 \%$ in overweight individuals and by two-to-three-fold in obese individuals compared to normal weight individuals. In the United States, more than $40 \%$ of the population do not participate in leisure-time physical activity, and for Latinos, they are $30 \%$ less likely to engage in physical activity as Whites (Obesity Action Coalition, 2015; The State of Obesity, 2014). The prevalence of these alarming statistics convinced the TC and the faculty mentor of the importance in conducting this CRM project focusing on "diabesity" and the Latino population. In the following sections, this paper includes details of the CRM project developed and implemented by the TC and other findings, reflections, and recommendations. The study outlines a collaborative effort between a math education professor and a mentored TC to help the TC understand and experience how culture connected to mathematics can shape teaching 
mathematics. Collaborative planning and development of methods and data collection guided the TC in investigating cultural relevancy when teaching mathematics, and to see results secondary students and their parents learning mathematics with a cultural connection. These objectives were intentionally designed to investigate the potential impact of 'diabesity through mathematics' on future mathematics teachers through the experiences of the TC and her faculty mentor and a consultant. The CRM project included math objectives connected to intentional Latino cultural perspectives in authentic settings.

\section{Methods and Data Collection}

\section{CRM Activities with the Four Latino Students and the Parents}

This section includes a brief description of the three CRM activities related to diabetes and obesity presented to four secondary Latino students and their parents. The case study involved four students and their respective parents, one parent per student with a total of four parents. The demographic pre-survey of student participants included questions about age, grade level, dominant language, cultural background, and birthplace. Education questions on the survey reported that the age level of students ranged from 14 to 18 years of age as there was one $8^{\text {th }}$ grade student, one $10^{\text {th }}$ grade student, one $11^{\text {th }}$ grade student, and one $12^{\text {th }}$ grade student. Two students stated that their dominant language was English and two stated that they were equally dominant in English and Spanish. The cultural background of all four students was Latino/Hispanic, and all but one was born in the USA. Their parents were all Latino/Hispanic, and their ages ranged from 30 to 40 years of age, and all but one was also born in the USA.

Prior to beginning the Power Point presentation, the following survey was given to students and parents (Table 1)

Table 1: Survey for students and parents before CRM activity SURVEY FOR STUDENTS AND PARENTS BEFORE CRM ACTIVITY

\section{SA-STRONGLY AGREE, A-AGREE, U-UNDECIDED, D-DISAGREE, SD- STRONGLY DISAGREE}

\begin{tabular}{|c|c|c|c|c|c|}
\hline 1. I like learning mathematics. & SA & $\mathbf{A}$ & $\mathbf{U}$ & $\mathbf{D}$ & SD \\
\hline 2. Mathematics is a subject I avoid. & SA & A & $\mathbf{U}$ & D & SD \\
\hline 3. My parent(s)/child help me to do mathematics. & SA & $\mathbf{A}$ & $\mathbf{U}$ & $\mathbf{D}$ & SD \\
\hline 4. I like learning mathematics with my parent(s)/child. & SA & $\mathbf{A}$ & $\mathbf{U}$ & $\mathbf{D}$ & SD \\
\hline 5. Mathematics is very useful. & SA & A & $\mathbf{U}$ & D & SD \\
\hline 6. Mathematics is difficult. & SA & $\mathbf{A}$ & $\mathrm{U}$ & $\mathbf{D}$ & SD \\
\hline 7. Mathematics can be connected to real life situations. & SA & A & $\mathbf{U}$ & $\mathbf{D}$ & SD \\
\hline 8. I believe mathematics and culture/cultural issues can be connected. & SA & $\mathbf{A}$ & $\mathbf{U}$ & D & SD \\
\hline 9. I have experience doing mathematics with cultural activities. & SA & A & $\mathbf{U}$ & $\mathbf{D}$ & SD \\
\hline
\end{tabular}




\begin{tabular}{|c|c|c|c|c|c|}
\hline 10. I am interested in culturally relevant mathematics. & SA & A & $\mathbf{U}$ & D & SD \\
\hline 11. I know how to use mathematics to help prevent/manage diabetes. & SA & $\overline{\mathrm{A}}$ & $\overline{\mathrm{U}}$ & $\mathbf{D}$ & SD \\
\hline 12. I know how to use mathematics to help prevent/manage obesity. & SA & $\mathbf{A}$ & $\mathbf{U}$ & $\mathbf{D}$ & SD \\
\hline 13. Mathematics makes me anxious. & SA & A & $\mathbf{U}$ & $\mathbf{D}$ & SD \\
\hline 14. I prefer not to study mathematics. & SA & A & $\mathbf{U}$ & $\mathbf{D}$ & SD \\
\hline \multicolumn{4}{|c|}{$\begin{array}{l}\text { OPEN ENDED QUESTIONS FOR STUDENTS AND PARENTS: } \\
\text { \#1. Do you think that relating mathematics to culture would make it more } \\
\text { interesting to learn? Why or why } \\
\text { not? } \\
\text { \#2. Could a better understanding of mathematics improve the decisions you } \\
\text { make in life? Explain how. }\end{array}$} & & \\
\hline \multicolumn{4}{|c|}{$\begin{array}{l}\text { \#3. Can involving parents in studying mathematics help their children like } \\
\text { mathematics more? Why or why } \\
\text { not? }\end{array}$} & & \\
\hline
\end{tabular}

The TC used information in her Power Point presentation compiled from sources such as the Center for Disease Control National Statistics report 2017; Mayo Clinic, 2015; Texas Health and Human Services, 2015) She included the major risk factors for getting diabetes; namely, ethnicity/race, family history, excess weight, and a sedentary life. In addition, conditions related to diabetes such as obstructive sleep apnea, colon cancer, cognitive impairment, cardiovascular disease, heart attack, stroke, kidney disease, urinary tract infections, and cancer in the bladder were also shared. The PowerPoint presentation was very effective in garnering the participant's interest in "diabesity".

Body Mass Index: Part one of the CRM activity introduced information about a person's body mass index (BMI) which is a simple index of weight-forheight that is commonly used to classify overweight and obesity in adults (Center for Disease Control and Prevention, 2004; World Health Organization, 2015). The formulas for calculating BMI are: (a) BMI= Weight $(\mathrm{kg}) \div[$ Height $(\mathrm{m})]^{2}$; or (b) BMI $=$ Weight $(\mathrm{lb}) \div[\text { Height(in) }]^{2} \times 703$. The participants calculated their BMI using both the metric and customary measurement formulas. A person's BMI is grouped into one of the following four categories: (a) Below 18.5 (Underweight); (b) 18.5 - 24.9 (Normal or Healthy Weight); (c) 25.0 - 29.9 (Overweight); and (d) 30.0 and above (Obese). These categories are the same for men and women of all body types and ages (CDC: About Adult BMI, 2015). The TC used the following table to calculate BMI of the participants in the study (see Table 2). 
Table 2: Calculation of BMI Activity

\section{ACTIVITY \#1: BMI}

Step 1: Measure current weight and height.

$$
\begin{array}{ll}
\text { HEIGHT: } & \text { inches } \\
\text { WEIGHT: } & \text { pounds }
\end{array}
$$

Step 2: Use weight and height measurements to find BMI.

Method \#1: Using pounds, lbs, and inches, in.

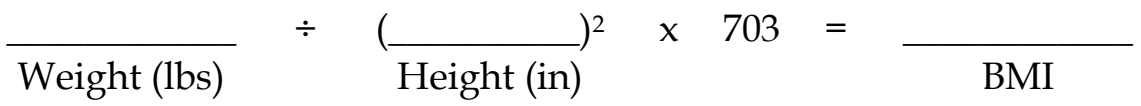

Method \#2: Using kilograms, $\mathrm{kg}$, and meters, $\mathrm{m}$.

A. Find weight in kilograms, kg.

$$
\text { Measurements for Converting: } \mathrm{lbs} \rightarrow \mathrm{kg} \text {. }
$$

$$
\begin{aligned}
& 1 \mathrm{~kg} \approx 2.2 \mathrm{lbs} \\
& \overline{\text { Weight (lbs) }} \div 2.2 \mathrm{lbs} / \mathrm{kg} \quad=\frac{}{\text { Weight }(\mathrm{kg})}
\end{aligned}
$$

B. Find height in meters, $m$.

$$
\text { Measurements for Converting: in } \rightarrow \mathbf{m} \text {. }
$$

$\overline{\text { Height (in) }}$

$$
\begin{gathered}
\mathbf{1} \text { in = 2.54 cm } \quad \mathbf{1 ~ m = 1 0 0 ~ c m} \\
\times \quad 2.54 \mathrm{~cm} / \text { in }
\end{gathered} \quad \div \quad 100 \mathrm{~cm} / \mathrm{m}=\frac{}{\text { Height }(\mathrm{m})}
$$

C. Calculate BMI.

$$
\overline{\text { Weight }(\mathrm{kg})} \div \overline{[\text { Height }(\mathrm{m})]^{2}} \div \overline{\text { BMI }}
$$

Step 3: Discuss the results.

A. Are the BMI's from Method 1 and Method 2 the same? Why or why not?

B. What does your BMI say about your health?

Balanced Diet: Part two of the CRM activity was about keeping a balanced diet to prevent obesity. Even though most of the world's population live in countries where overweight and obesity kills more people than underweight, obesity is preventable. How? Mainly by an appropriate diet. However, when the word "diet" is heard, many people assume it is a change made to one's food intake for the sole purpose of weight loss. A balanced diet, however, is not a trend but a lifestyle. A balanced diet means choosing the right foods that will help the body to perform at its highest potential and can also prolong life, help to maintain a healthy weight, and increase positive moods. The United States Department of Agriculture has developed guidelines to help determine the proper amount of calorie intake for different ages and lifestyles (Healthline, 2012). According to this source, "the average person needs to eat 
about 2,000 calories every day to maintain their weight". However, a person's specific daily calorie intake can vary depending on their age, gender, and physical activity level. For this CRM activity, the participants used the "My Fitness Pal" website (2015) to select foods the participants had eaten or would want to eat, each with a calorie counter. (See Table 3).

Table 3: Activity \#2

\begin{tabular}{|l|c|c|c|c|}
\hline \multicolumn{5}{|c|}{ Step 1: Fill out the food chart below with yesterday's meals. } \\
\cline { 2 - 5 } & Main Dish & Side Dish 1 & Side Dish 2 & Beverage \\
\hline Breakfast & & & & \\
\hline Snack 1 & & & & \\
\hline Lunch & & & & \\
\hline Snack 2 & & & & \\
\hline Dinner & & & & \\
\hline
\end{tabular}

Did you consume any other foods and/or beverages yesterday? $\square$ Yes.

No.

Step 2: Find calories for each item (using website).

\begin{tabular}{|c|c|l|l|l|}
\cline { 2 - 5 } & Main Dish & Side Dish 1 & Side Dish 2 & Beverage \\
\hline Breakfast & & & & \\
\hline Snack 1 & & & & \\
\hline Lunch & & & & \\
\hline Snack 2 & & & & \\
\hline Dinner & & & & \\
\hline
\end{tabular}

Step 3: Calculate total calories consumed yesterday.

Total calories consumed $=$ Step 4: Discuss the results.

A) When eating/drinking yesterday, did you stop to check how many calories and/or servings were in the food/beverage before consuming it?

B) Referring to the table in the brochure, was your calorie consumption above or below the recommended levels of calorie intake for your age and lifestyle?

C) What does your calorie consumption foreshadow concerning your health?

Regular Exercise: Part three of the CRM activity was about the importance of regular exercise to avoid being overweight and/or obese, and indirectly, to prevent diabetes. "Physical inactivity" or living a "sedentary lifestyle" are frequently mentioned as causes leading to the development of chronic diseases since being inactive contributes to weight gain. For one's body to maintain a healthy weight, the calories consumed must be balanced out by the calories burned. When this scale is unbalanced, this is when weight gain or weight loss occurs. The Centers for Disease Control and Prevention suggests appropriate amounts of exercise to maintain a healthy weight and lifestyle (CDC: Physical Activity, 2015). For this CRM activity, the participants used the 
"What's Cooking America" website (2015) to select both moderate and vigorous exercises for the purpose of burning calories. They calculated how many calories they could burn per minute. The following table provides information for those calculations (Table 4).

Table 4: Exercise and Activity Calculations ACTIVITY \#3: APPROPRIATE EXERCISE

1. Bicycling (5.5 MPH) - Moderate

Calories Burned per Pound per Minute (CPM)

2. Bicycling (9.5 MPH) - Vigorous .029

3. Dance, Aerobic (Medium) - Moderate .045

4. Dance, Aerobic (Intense) - Vigorous .046

5. Grocery Shopping - Moderate .061

6. Jumping Rope (70 Jumps/Minute) - Moderate

7. Jumping Rope (125 Jumps/Minute) - Vigorous .074

8. Mowing the Lawn - Moderate .080

9. Running (8-Minute Mile) - Moderate .051

10. Running (9-Minute Mile) - Vigorous .095

11. Squats - Vigorous .087

12. Walking, Asphalt Road (Normal Pace) - Moderate .096

13. Walking, Fields and Hills (Normal Pace) .036 Moderate

14. Weight Training (Free Weights) - Vigorous $\quad 039$

15. Weight Training (Circuit Training) - Moderate $\quad 023$

Step 1: Choose five moderate-intensity exercises from above.

\#1:

\#2:

\#3:

\#4:

\#5: 
Step 2: Calculate calories burned for each exercise performed for 30-minutes, where $\mathrm{CPM}=$ calories per minute

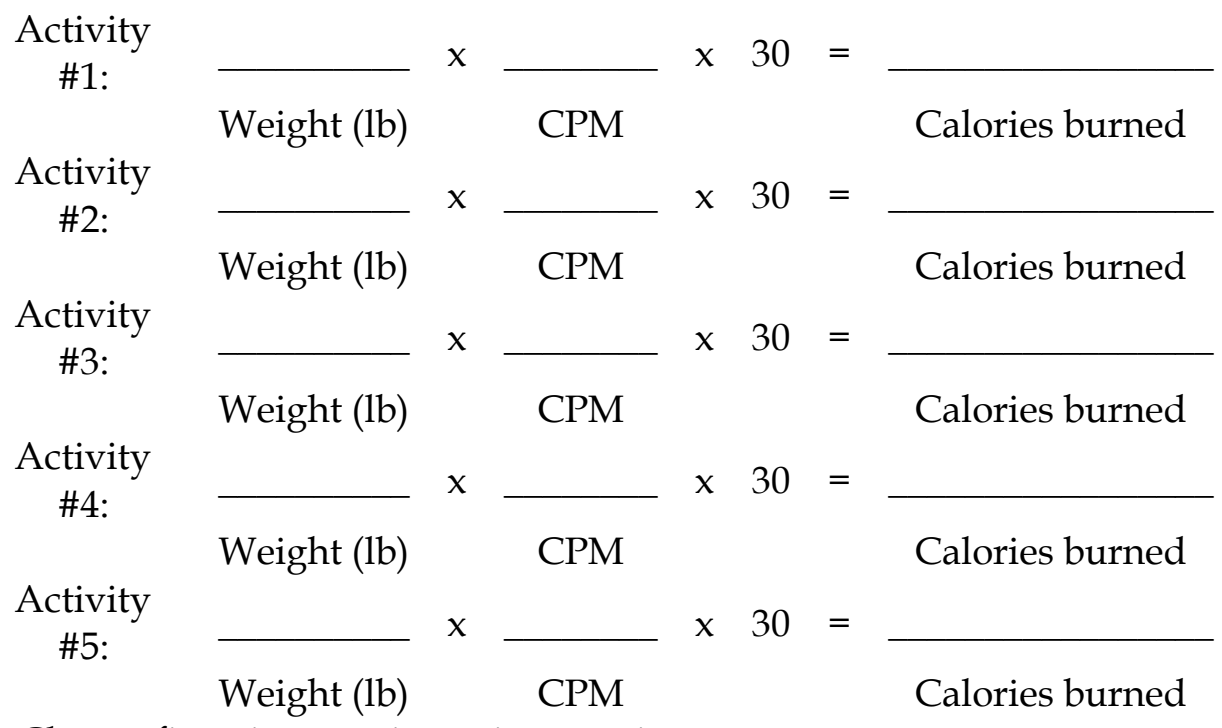

Step 3: Choose five vigorous-intensity exercises.

\#1:

\#2:

\#3:

\#4:

\#5:

Step 4: Calculate calories burned for each exercise performed for 30-minutes, where $\mathrm{CPM}=$ calories per minute

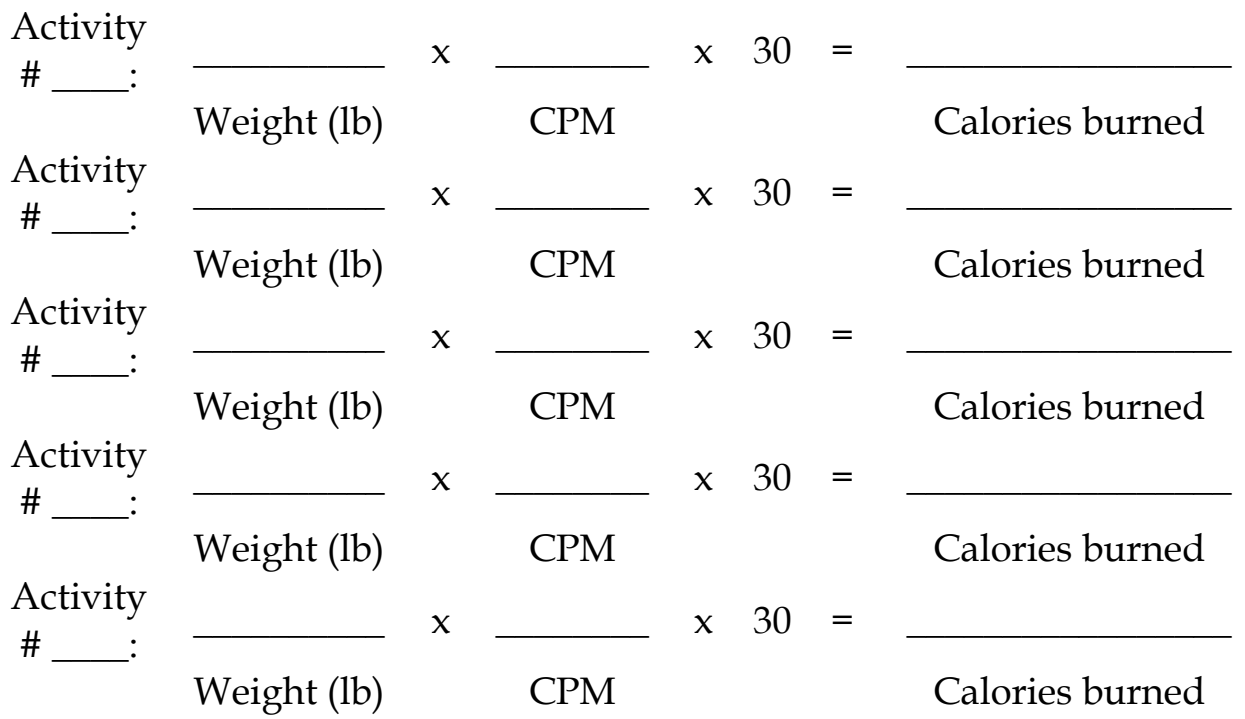

Step 5: Analyze results of the exercise activity with suggested calorie intake. 


\section{Suggested calorie intake for age and lifestyle: \\ Calories burned doing five moderate-intensity level exercises:}

Calories burned doing five vigorous-intensity level exercises:

Step 6: Discuss the results.

A) With a balanced diet and five moderate-level exercises per week, would you be able to achieve and maintain a healthy weight (and respectively, a normal $\mathrm{BMI})$ ?

B) With a balanced diet and five vigorous-level exercises per week, would you be able to achieve and maintain a healthy weight (and respectively, a normal BMI)?

Below are two photos taken of the student-parent teams as they worked on the mathematics portion of the CRM activities. The participants (students with parents) worked together with pen and paper, a TI-83 calculator and a computer. The computer was used during the balanced diet activity to find the number of calories in each item of food they consumed the day before, and in the exercise activity to find the amount of exercise required to burn off calories.

Photos: Student and parent teams working on CRM activities at computer stations
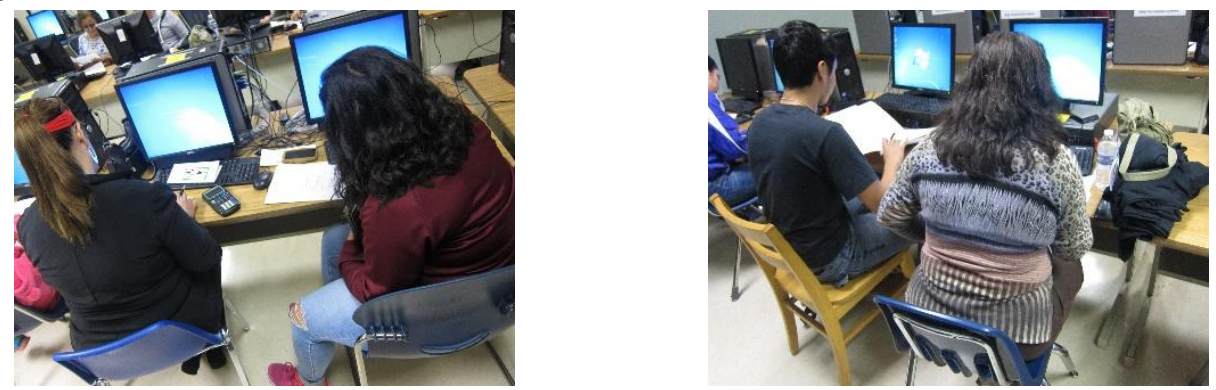

\section{Post-surveys Completed following the CRM Activity}

The following surveys were given to the students and their parents following the CRM activity. The first post-activity survey was designed to investigate the first research question, "What mathematics did the Latino secondary student, Latino parents and the TC show and report learning from the CRMA?" (Table 5).

Table 5: Post- Survey Regarding Mathematics Content Knowledge FIRST SURVEY FOR STUDENTS AND PARENTS AFTER ACTIVITY SA-STRONGLY AGREE, A-AGREE, U-UNDECIDED, D-DISAGREE, SDSTRONGLY DISAGREE

\begin{tabular}{|l|l|l|l|l|l|l||}
\hline 1.I like learning mathematics. & SA & $\mathbf{A}$ & $\mathbf{U}$ & $\mathbf{D}$ & $\mathbf{S D}$ \\
\hline \hline 2.Mathematics is a subject I avoid. & & $\mathbf{S A}$ & $\mathbf{A}$ & $\mathbf{U}$ & $\mathbf{D}$ & $\mathbf{S D}$ \\
\hline \hline 3.My parent(s)/ child help me to do mathematics. & & $\mathbf{S A}$ & $\mathbf{A}$ & $\mathbf{U}$ & $\mathbf{D}$ & $\mathbf{S D}$ \\
\hline \hline 4.I like learning mathematics with my parent(s)/child. & & SA & $\mathbf{A}$ & $\mathbf{U}$ & $\mathbf{D}$ & $\mathbf{S D}$ \\
\hline
\end{tabular}




\begin{tabular}{|c|c|c|c|c|c|}
\hline 5.Mathematics is very useful. & SA & A & $\mathbf{U}$ & D & SD \\
\hline 6.Mathematics is difficult. & SA & A & $\mathbf{U}$ & $\mathbf{D}$ & SD \\
\hline 7.Mathematics can be connected to real life situations. & SA & A & $\overline{\mathrm{UU}}$ & $\mathbf{D}$ & SD \\
\hline 8.I believe mathematics and culture/cultural issues can be connected. & SA & $\mathbf{A}$ & $\mathrm{U}$ & $\mathbf{D}$ & SD \\
\hline 9.I have experience doing mathematics with cultural activities. & SA & $\mathbf{A}$ & $\mathbf{U}$ & $\mathbf{D}$ & SD \\
\hline 10.I am interested in culturally relevant mathematics. & SA & $\mathbf{A}$ & $\mathbf{U}$ & $\bar{D}$ & SD \\
\hline 11.I know how to use mathematics to help prevent/manage diabetes. & SA & $\mathbf{A}$ & $\mathbf{U}$ & $\mathbf{D}$ & SD \\
\hline 12.I know how to use mathematics to help prevent/manage obesity. & SA & A & $\mathbf{U}$ & $\mathbf{D}$ & SD \\
\hline 13.Mathematics makes me anxious. & SA & A & $\mathrm{U}$ & D & SD \\
\hline 14.I prefer not to study mathematics. & SA & $\mathbf{A}$ & $\mathbf{U}$ & $\mathbf{D}$ & SD \\
\hline \multicolumn{6}{|c|}{$\begin{array}{l}\text { \#1. Do you think that relating mathematics to culture would make it more } \\
\text { interesting to learn? Why or why not? }\end{array}$} \\
\hline \multicolumn{6}{|c|}{$\begin{array}{l}\text { \#2. Could a better understanding of mathematics improve the decisions you } \\
\text { make in life? Explain } \\
\text { how. } \\
\text { \#3. Can involving parents in studying mathematics help their children like } \\
\text { mathematics more? Why or why not? }\end{array}$} \\
\hline
\end{tabular}

The TC administered a second survey intended to answer the research question. "What cultural reactions did the Latino secondary student and Latino parents report learning from the CRMA?" Table 6 provides questions from that survey.

Table 6: Post-Survey Regarding Knowledge of Diabetes of Obesity Among Latinos

SECOND SURVEY FOR STUDENTS AND PARENT(S) AFTER ACTIVITY

SA-STRONGLY AGREE, A-AGREE, U-UNDECIDED, D-DISAGREE, SDSTRONGLY DISAGREE

1. Before this math activity, I was not aware of how widespread Diabetes was among the Latino population.

2. Before this math activity, I was not aware of how widespread Obesity was among the Latino population.

3. Before this math activity, I was not aware that mathematics can help the Latino population to understand how to prevent diabetes. 
4. Before this math activity, I was not aware that mathematics can help the Latino population to understand how to prevent obesity.

SA A U D SD

5. Before this math activity, I had never calculated calories in a diet.

\begin{tabular}{lll}
\hline $\mathbf{A} A$ & $\mathbf{A}$ & $\mathbf{D D}$ \\
\hline
\end{tabular}

6. Before this math activity, I had never calculated my Body Mass Index.

7. Before this math activity, I had never calculated calories burned through exercise.

ANY ADDITIONAL COMMENTS OR REMARKS:

\section{Results}

\section{Pre- and Post-Survey}

Pre- and post-surveys were used to analyze the participant's reactions to the CRM project, as well as to answer questions posed earlier. The work completed by each secondary Latino student and the parent using mathematics in the CRM activities were also analyzed. Lastly, the TC wrote a semi-structured reflection paper regarding what she learned from the CRM project, what she learned from the secondary students and the parents, and any salient experience or conversation she remembered from the CRM project. In addition, she was interviewed by both faculties to find relevant reactions from conducting this CRM project, and the faculty reviewed and summarized her responses. Triangulation was achieved by using multiple data sources and validating each piece of information with at least one other data source (Lincoln \& Guba, 1985). In this case study, data sources and documentation included pre/post surveys, the semi-structured reflection paper and interviews with the TC by the faculty mentor and the consultant. Inter-rater reliability was calculated for interview data and randomly selected surveys and was calculated at $89 \%$, a high level of agreement.

On the pre- and post-survey of students and parents, the same fourteen (14) Likert-type items shown on Table 1 were tabulated with the following choices: Strongly Agree, Agree, Undecided, Disagree, and Strongly Disagree. Table 4 summarizes the cumulative responses for students and parents for the Strongly Agree and Agree choices. A comparison between the pre-survey and the postsurvey Likert-item results show that after participating in the CRM activities, the participants made positive gains in how the participants viewed mathematics, cultural activities, and how to use mathematics to help prevent and manage diabetes and obesity. Although the sample size is relatively small, the results show a trend in identifying important steps toward informing Hispanics about "diabesity". The survey data collected are illustrated in the following table (Table 7). 
Table 7: Pre- and Post-Survey Responses in the Strongly Agree and Agree Categories

\begin{tabular}{|l|l|l|l|}
\hline Statement & \multicolumn{1}{|c|}{$\begin{array}{c}\text { Pre } \\
\text { SA,A }\end{array}$} & $\begin{array}{c}\text { Post } \\
\text { SA,A }\end{array}$ & \multicolumn{1}{|c|}{ Change } \\
\hline 1. I like learning mathematics. & $100 \%$ & $100 \%$ & 0 \\
\hline 2.Mathematics is a subject I avoid. & $87.5 \%$ & $37.5 \%$ & $-50.0 \%$ \\
\hline 3.My parent(s)/child help me to do mathematics. & $62.5 \%$ & $75 \%$ & $+12.5 \%$ \\
\hline 4.I like learning mathematics with my parent(s)/child. & $62.5 \%$ & $75 \%$ & $+12.5 \%$ \\
\hline 5.Mathematics is very useful. & $100 \%$ & $100 \%$ & 0 \\
\hline $\begin{array}{l}\text { 6.Mathematics is difficult. } \\
\text { 7.Mathematics can be connected to real life situations. }\end{array}$ & $100 \%$ & $87.5 \%$ & $-12.5 \%$ \\
\hline $\begin{array}{l}\text { 8. I believe mathematics and culture/cultural issues can be } \\
\text { connected. }\end{array}$ & $75 \%$ & $100 \%$ & 0 \\
\hline $\begin{array}{l}\text { 9. I have experience doing mathematics with cultural } \\
\text { activities. }\end{array}$ & $12.5 \%$ & $62.5 \%$ & $+50.0 \%$ \\
\hline $\begin{array}{l}\text { 10. I am interested in culturally relevant mathematics. } \\
\text { diabetes. }\end{array}$ & $50 \%$ & $87.5 \%$ & $+37.5 \%$ \\
\hline $\begin{array}{l}\text { 11. I know how to use mathematics to help prevent/manage } \\
\text { obesity. }\end{array}$ & $12.5 \%$ & $75 \%$ & $+62.5 \%$ \\
\hline 13. Mathematics makes me anxious. & $12.5 \%$ & $75 \%$ & $+62.5 \%$ \\
\hline 14. I prefer not to study mathematics. & $62.5 \%$ & $37.5 \%$ & $-25.0 \%$ \\
\hline
\end{tabular}

Regarding pre-survey of students and parents with 3 open-ended questions, when first asked, "Do you think that relating mathematics to culture would make it more interesting to learn? Why or why not?", some of the responses by the students were: (1) "I agree that relating mathematics to culture would make it more interesting to learn because you have two different subjects"; (2) "Yes, because by combining both topics, it will be a more interesting topic to learn"; and (3) "Yes, because it wouldn't just be about culture but about using numbers to help understand the topic". Some of the responses by the parents were: (1) "Yes, because there should be culture to solve mathematics"; (2) "Of course, it would be better and/or more interesting; and (3) Yes, because in all activities mathematics is always used".

Secondly on the pre-survey, when asked, "Can a better understanding of mathematics improve the decisions you make in life? Explain how.", some of the responses by students were: (1) "Yes, by knowing the difference in cost when shopping, I can learn about taxes"; (2) "Yes, because by knowing more math, you'd learn more and make better decisions"; and (3) "Yes, because I believe math has to deal with everything in the world and it can change people's perspectives". Some of the responses by parents were: (1) "Yes, it is very important"; (2) "I believe so, because they are very related"; and (3) "Yes, because in every situation there is a need to count or use math".

Thirdly on the pre-survey, when asked, "Can involving parents in studying mathematics help their children like mathematics more? Why or why 
not?", some of the responses by students were: (1) "Yes, they can help them/us with our homework"; (2) "Yes, because the child will be motivated by seeing the parent excited to learn math"; and (3) "Yes, because they might help us understand more about how we can use it and make it possible for us not to think it's difficult". Some of the responses by parents were: (1) "Yes, because mathematics is very interesting"; (2) "Of course, because children learn more when they see their parents doing new things and we, the parents, need to learn new things"; and (3) "When they see the support of their parents, they are less lazy when studying".

On the post-survey of students and parents with 3 open-ended questions regarding all the participants, when first asked, "Do you think that relating mathematics to culture would make it more interesting to learn? Why or why not?", some of the responses by students were: (1) "Yes, because you are combining totally different subjects together"; (2) "Yes, because it can give us warnings about the real life we are living"; and (3) "Yes, it'll bring more learning styles". Some of the responses by parents were: (1) "Yes, because it advises you on your health"; (2) After this class, it is very interesting to me".

Secondly on the post-survey, when asked, "Could a better understanding of mathematics improve the decisions you make in life? Explain how." some of the responses by students were: (1) "Yes, not only by knowing differences in taxes but on how to lose weight"; (2) "Yes, because you can estimate what can happen to someone with different choices"; and (3) "Yes, it can help measure the amount of calories you eat and/or burn". Some of the responses by parents were: (1) "Yes, I am now going to make better decisions about what I am going to eat"; (2) "Yes, when it is time to prepare the meals for my family, I will make better choices".

And thirdly on the post-survey, when asked, "Can involving parents in studying mathematics help their children like mathematics more? Why or why not?" some of the responses by students were: (1) "Yes, because they impact us by their manners with us"; (2) "Yes, because they can get us more involved"; and (3) "Yes, because the child tends to follow in the parent's footsteps". Some of the responses by parents were: (1) "Yes, because it is important in every area of your life"; and (2) "Yes, it is fun and practical to involve ourselves in mathematics with our children and better our health".

\section{Final (2nd) Post-Survey Results}

The final post-survey of students and parents that included seven (7) Likert-type questions (Table 6), the results for the participants combined indicate that prior to this CRM project: (1) $87.5 \%$ percent stated they were not aware of how widespread diabetes was among the Latino population; (2) $87.5 \%$ percent stated that they were not aware of how widespread obesity was among the Latino population; (3) $87.5 \%$ percent stated that they were not aware that mathematics can help the Latino population understand how to prevent diabetes; (4) $87.5 \%$ percent stated that they were not aware that mathematics can help the Latino population understand how to prevent obesity; (5) $62.5 \%$ percent stated that they had never calculated calories in a diet; (6) $75 \%$ percent stated that they had never calculated their Body Mass Index; and (7) 75\% percent stated that they had never calculated calories burned through exercise. Therefore, an 
overwhelming majority of participants found the CRM activities both informational and educational.

\section{CRM Case Study Project Results}

The TC and both faculty members (Mathematics educator and Science educator/consultant) read, studied, and analyzed the survey data and responses to the open-ended questions from the secondary students and parent surveys data collected during the CRM activities. In addition, the TC provided her own reflections of the culturally relevant mathematics project with the families which were analyzed by the faculty. The TC was also interviewed by both faculties to find relevant reactions from conducting this CRM project, and both faculties reviewed and summarized her responses. The results from these interviews are reported in a separate qualitative study.

Regarding the first research question, "What mathematics did the Latino secondary student, Latino parents and the TC show and report learning from the CRMA?", we found that at the beginning of the project, many participants agreed that they liked learning mathematics. They also agreed that mathematics is useful and can be connected to real life situations. However, initially, the participants were surprised because they had not realized they were using mathematics in things such as caloric values for a food dish or in calculating how much would be needed to double a serving or divide a serving in two equal parts. Other responses stated that a knowledge and/or understanding of mathematics can help them calculate taxes and to save money. In the CRM activities they used the CRM BMI activity to calculate if their health was at risk, and the CRM Diet and Exercise activities to help them make better food intake choices and exercises for burning calories that could help them prevent, and possibly manage, diabetes and obesity. Also, from the analyses of the responses, the participants realized that their appreciation of mathematics increased, perhaps because of the great benefits they noted while using mathematics to help improve their health. They also saw that mathematics can be connected to real life situations. All participants accepted the idea that math is useful and relevant in everyday life despite lacking experience in using mathematics prior to this project. They saw how useful and relevant mathematics can be when it comes to important aspects of their lives, such as their health. The TC reported that by doing the CRM project with students and parents, she was informed that the CRM activities did help the participants obtain important mathematics calculations to help them manage diabetes and obesity.

The second research question, "What cultural reactions did the Latino secondary student, Latino parents and the TC report learning from the CRMA?", results revealed that the culture of the participants was still very intact since each of the students were either first- or second-generation U.S.A. citizens whose families migrated to the United States from Mexico. Analysis of the pre-survey responses showed that neither the students nor the parents had connected the concept of associating mathematics with culture despite believing that it was possible to connect mathematics to cultural issues. When questioned on their interest in culturally relevant mathematics, half of the group agreed on having an interest while the other half responded that they were undecided. Responses about the CRM activities, prior to the project, reflected a lack of knowledge 
about how to use mathematics to help prevent or manage the very prevalent "diabesity" that affects a large majority of Latinos. From analysis of the first post-survey, their newfound understanding concerning culture and mathematics was evident in their responses with phrases such as "more interesting" used in their responses. Most responses indicated a positive shift toward agreeing more to having experience with CRM activities. Other responses reflected a positive change in understanding the connection between culture and mathematics. After the project, the participants felt more confident about using mathematics to help them make better choices about food intake and exercises to prevent and/or manage diabetes and obesity.

\section{Conclusions and Lessons Learned}

The TC's reflection paper revealed that the culturally relevant mathematics activities with the four Latino students and the parents served as an authentic learning experience for her. By mentoring the TC to do this CRM project with students and parents, both faculty affirmed that she acquired necessary perspectives to become a culturally responsive teacher especially because the TC reported on her reflection paper: "this was a good project because it gave me a view of parental involvement and I gained confidence in working with both secondary level students and parents in doing culturally relevant mathematics activities that improved their knowledge about diabetes and obesity". Engaging the TC in developing and implementing a CRM project provided her with opportunities for active learning and confidence building in teaching relevant mathematical topics. The TC learned through practice about the importance of culturally relevant mathematics with family engagement.

When analyzing the TC's reflection paper after the CRM culminated with the four Latino students and their parents, changes on the $\mathrm{TC}^{\prime}$ s perceptions toward Latino students and parents were apparent. Genuine interactions with Latino students and parents doing CRM activities about diabetes and obesity allowed the TC to examine what she knew about Latino families and their perceptions about these prevalent diseases among the Latino population. Her prior knowledge about engaging Latinos or parents with culturally relevant mathematics activities was solely based on her preconceptions resulting from information learned from reading a few published journal papers on the topic. However, with this CRM project, the TC was exploring what her participants (the Latino students and parents) learned from the opportunity she had to interview and interact with them while doing CRM activities. She recognized and stated that "the four Latino students and their parents showed genuine interest in learning about diabetes and obesity". In addition, the TC stated that "they were very engaged in the topics about BMI, diet, exercise".

Any apprehension the TC had about doing the CRM activities with families was diminished because her experience was very positive, rewarding, and valuable. Regarding the parents, the TC realized that Latino parents value education and are highly supportive of their children's schooling even when facing economical, linguistic, and cultural barriers. Even though the TC is Latino, she had never been exposed to interacting with Latino parents in the context of schooling, and she did not understand the importance of home-school partnerships prior to the project. This is evident in her reflection statement 
where she stated, "prior to doing this project, I was not aware of the importance of involving parents in education". Furthermore, in her reflection paper, the TC noted that Latino parents do care and would like to be involved in their children's education but might not do so due to certain barriers. For example, the TC wrote on her reflection "I noticed from talking and listening to some of the parents that they enjoyed being involved in their children's education but some of them lacked English-speaking ability." The TC also described on her reflection paper, "There are many things I learned from participating in this project, but the most important thing was that the Latino students and parents were very interested in the topics of diabetes and obesity. Plus, I noticed that the parents enjoyed interacting with their children and they showed great interest in using math in each activity. However, a few times, the parents indicated that it took an invitation to participate in a project like this to actually become actively involved in their children's education."

Having the opportunity to interact with Latino students and parents in the context of CRM activities provided the TC with the opportunity to learn about diabetes and obesity and how to combat these detrimental diseases among Latinos. This experience gave the TC an authentic venue for learning to teach as a culturally responsive teacher. The CRM project gave her the opportunity to make valuable and meaningful connections with what she had read in the literature about culturally relevant mathematics. In addition, her CRM project provided her the opportunity to relate to home-school connections, especially with non-English speaking Latino students and their parents.

\section{Recommendations and Implications: CRM Teaching and "Diabesity"}

Having completed this CRM project, both the TC and the faculty suggest that educators interested in doing a similar CRM project with a TC or a group of TCs, or with another targeted audience begin by having a group discussion regarding what culturally relevant pedagogy means, and what characteristics a culturally relevant mathematics activity should have. This paper can serve as a basis for doing such.

In teaching about the cultural prevalence of diabetes and obesity among the Latino population it is recommended that TCs be asked what they know about the diabetic and obesity epidemics among Latinos. Having group discussions with TCs regarding the cultural prevalence of diabetes and obesity among the Latino population and the implications for their health status are important. For example, factors such as: diet, weight, body mass index, physical exercise, and sedentary lifestyle, can be explored to enhance their understanding of these diseases.

In conclusion, TCs can be challenged to find information on the factors that are directly or indirectly related to "diabesity", and they can be furthered challenged to use mathematics to help teach their future students or others, to prevent and manage these diseases, just like the TC did in this project. Overall, any TC or in-service teacher interested and committed to culturally relevant teaching can develop and implement CRM activities to bridge home with school in more effective ways. 


\section{References}

America's Health Rankings (2018). United Health Foundation. Retrieved May 10, 2019 https://www.americashealthrankings.org/learn/reports/2018-annual-report

CDC: Centers for Disease Control and Prevention (2015) "About Adult BMI" Retrieved May 7, 2019 from http://www.cdc.gov/healthyweight/assessing/bmi/adult_bmi/

CDC: Centers for Disease Control and Prevention (2015) "Adult Obesity Causes \& Consequences". Retrieved May 7, 2019 http://www.cdc.gov/obesity/adult/causes.html

CDC: Centers for Disease Control and Prevention (2015) "Basics about Diabetes". Retrieved May 7, 2019 from http://www.cdc.gov/diabetes/basics/diabetes.html

CDC: Centers for Disease Control and Prevention (2015) “BMI Calculator. Retrieved May 7, 2019 from https://www.cdc.gov/healthyweight/assessing/bmi/adult_bmi/english_bmi_ calculator/bmi_calculator.html

CDC: Centers for Disease Control and Prevention (2015) "How much physical activity do adults need?" Retrieved May 7, 2019 from http://www.cdc.gov/physicalactivity/basics adults/index.htm

CDC: Center for Disease control and Prevention (2017) "National Diabetes Statistics Report, 2017. Retrieved May 7, 2019 from https://www.cdc.gov/diabetes/pdfs/data/statistics/national-diabetes-statisticsreport.pdf

CDC: Centers for Disease Control and Prevention (2015) "Prediabetes". Retrieved May 7, 2019 from http:/ / www.cdc.gov/diabetes/basics/prediabetes.html

Choose My Plate (2015). Retrieved May 7, 2019 from https://www.choosemyplate.gov/physical-activity-calories-burn

Clark, P., Zygmunt, E., Clausen, J., Mucherah, W., \& Tancock, S. (2015). Transforming teacher education for social justice. New York, NY: Teachers College Press.

Endocrineweb. (2015) Retrieved on May 10, 2019 from https://www.endocrineweb.com/

Epstein, J. L., Jung, S. B \& Sheldon, S. B. (2018). Toward Equity in School, Family, and Community Partnerships. New York, NY: Wiley https://doi.org/10.1002/9781119083054.ch26

Farag, Y. \& Gaballa, M. (2011). Diabesity: an overview of a rising epidemic. Nephrology Dialysis Transplantation, (26) 1, 28-35. Retrieved May 9, 2019 from https://academic.oup.com/ndt/article/26/1/28/1838186

Grant, K, B. and Ray, J. A. (eds). (2018). Home, School, and Community Collaboration: Culturally Responsive Family Engagement. Thousand Oaks, CA: Sage

Healthline (2012) "Balanced Diet". Retrieved September 25, 2015 http:/ / www.healthline.com/health/balanced-diet\#Importance3

International Diabetes Federation (2015). "About Diabetes" Retrieved September 29, 2015 from http://www.idf.org/about-diabetes

Ladson-Billings, G. (2014). Culturally relevant pedagogy 2.0: aka the remix. Harvard Educational Review 84 (1), 74-84.

Ladson-Billings, G. (2018). The social funding of race: The role of school, Peabody Journal of Education, 93(1), 90-105. DOI: 10.1080/0161956X.2017.1403182

Lincoln, Y., \& Guba E. (1985). Naturalistic Inquiry. Beverly Hills, CA: Sage.

Mayo Clinic (2015) "Diabetes: Definition". Retrieved September 25, 2015 from http://www.mayoclinic.org/diseases- 
conditions/diabetes/basics/definition/con20033091?_ga $=1.193676333 .1645673660 .1446579185$

McCollough, C., Ramirez, O. \& Carranza-Alvarez, A. (2018). A case study using Culturally relevant math. Academic Exchange Quarterly, Fall Volume, 7-17. Retrieved May 9, 2019 http:// rapidintellect.com/AEQweb/5900-how- to.pdf

McCollough, C. and Ramirez, (2012) Cultivating culture: Preparing future teachers for diversity through family learning events. School Science and Mathematics, (112) 7, $443-451$.

McCollough, C. (2011). Creating A college going culture: Disadvantaged high school students teaching family science. The Science Teacher (78), 3, 51-55.

https://s3.amazonaws.com/nstacontent/tst1103_51.pdf?AWSAccessKeyId=AK IAIMRSQAV7P6X4QIKQ\&Expires=1557483262\&Signature=1UXcjYmr\%2b4nqE QsW61cJKtui2fo\%3d

My Fitness Pal (2015). Retrieved May 7, 2019 from https://www.myfitnesspal.com/food/calorie-chart-nutrition-facts

National Research Council (2013). Next Generation Science Standards: For States, By States. Washington, DC: The National Academies Press. Retrieved May 9, 2019 From https://doi.org/10.17226/18290.

NBC News (2004). Retrieved May 9, 2019 from http://www.nbcnews.com/id/5820571/ns/health-health_care/t/rio-grandevalley-among-unhealthiest-areas/\#.ViEPGH6rSUk

Obesity Action Coalition (2015) "Obesity statistics". Retrieved May 9, 2019 from http://www.obesityaction.org/educational-resources/obesity-statistics-fact sheets

Olivos, E., \& Mendoza, M. (2010). "Immigration and educational inequality: Examining Latino immigrant parents' engagement in U.S. public schools". Journal of Immigrant \& Refugee Studies, 8(3), 339-357.

Potter, D. \& Morris, D. (2016) Family and school experiences in racial/ethnic academic achievement gaps, A cumulative perspective. Sociological Perspectives 60(1), 132167.

Ramirez, O., McCollough, C. \& Diaz, Z. (2016). Creating a model of acceptance: Preservice teachers interact with non-English speaking Latino parents using culturally relevant math and science activities at family learning events. School, Science and Mathematics 116 (1), 43-54.

Ramirez, O. McCollough, C. and Diaz, Z. (2015) The Quinceanera Event : Pre- service teachers implementing a culturally relevant math activity in a Hispanic Community Journal of Mathematics and Culture, 8 (2), 57-69.

Ramirez, O. and McCollough, C. (2012). La Loteria: Using a culturally relevant math activity with preservice teachers at a family math learning event. Teaching for Excellence and Equity In Mathematics.(4),1, 24-33.

Settlage, J., \& Southerland, S. (2018). Writing worth reading: science methods textbooks and science education articles. Retrieved May 9, 2019 from http://hf4vl6dz9y.search.serialssolutions.com/?id=doi:10.1002/sce.21342\&sid= wiley\&iuid $=3156832 \&$ date $=2018 \& j$ ititle $=$ Science + Education $\&$ volume $=102 \&$ atitle =Writing+worth+reading:+Science+methods+textbooks+and+science+educatio $\underline{\mathrm{n}+\text { articles\&genre }=\text { article\&spage }=447 \& \text { issue }=3 \& \text { title }=\text { Science }+ \text { Education\&issn }=0}$ 036-8326\&epage $=451$

The State of Obesity (2014). "Obesity Prevention in Latino Communities" September $2014 . \quad$ Retrieved May 1, 2019 from http://stateofobesity.org/disparities/latinos/

Texas Health and Human Services (2015). Diabetes Prevention and Control Program: Reports \& Data. Retrieved on May 7, 2019 from https://www.dshs.texas.gov/txdiabetes/ 
U.S. Department of Health and Human Services Office of Minority Health (2017) "Obesity and Hispanic Americans" October 16, 2013. Retrieved May 9, 2019 from https://minorityhealth.hhs.gov/omh/browse.aspx?lvl=4\&lvlid=70

U.S. News and World Report (2018-A). Battle on the Border. Retrieved on May 7, 2019 from https://www.usnews.com/news/healthiest-communities/articles/2018-0516/a-battle-for-community-health-in-texas-rio-grande-valley

U.S. News and World Report, 2018-B. Feast or Famine South Texas. Retrieved on May 7, 2019 https://www.usnews.com/news/healthiest-communities/articles/201805-16/feast-or-famine-food-deserts-a-problem-in-texas-rio-grande-valley

WebMD (2014) "Obesity - Topic Overview" July 25, 2014. Retrieved September 25, 2015 from http://www.webmd.com/diet/obesity/obesity-overview

What's Cooking America (2015) "What about Exercise?: Calorie Burn Chart - Intensity Workout Chart". Retrieved September 26, 2015 http://whatscookingamerica.net/Information/CalorieBurnChart.htm

World Health Organization (2015) "Obesity and Overweight" January 2015. Retrieved September.

Valenzuela, A. (2016). Growing Critically Conscious Teachers: A Social Justice Curriculum for Educators of Latino/a Youth. New York, NY: Teachers College Press.

Zygmunt, E., Cipollone, K., Tancock, S., Clausen, J., Clark, P., \& Mucherah, W. (2018). Loving Out Loud: Community Mentors, Teacher Candidates, and Transformational Learning Through a Pedagogy of Care and Connection. Journal of Teacher Education, 69(2), 127-139. 